\title{
Increased Urban Heat Island Effect due to Building Height Increase
}

\author{
M. G. Bennet ${ }^{a}$ and C. M. Ewenz ${ }^{\text {a }}$ \\ ${ }^{a}$ School of the Environment, Flinders University, Adelaide, Australia \\ Email: Caecilia.Ewenz@flinders.edu.au
}

\begin{abstract}
An increase in urban population with only limited space to extend urban development forces city planners to think upwards. Adelaide, South Australia is one example where height restrictions in the central business district (CBD) were recently lifted to allow for a projected increase in urban population. The city provides a unique study area for the analysis of the urban induced heat variation. The main CBD is small compared to most cities around the world. The CBD covers only four square kilometres and is surrounded by a 500 metre wide parkland belt with sparse vegetation.
\end{abstract}

Adelaide's temperature distribution has been monitored by twenty temperature sensors in the CBD and parklands since winter 2010. The observations exhibit a maximum temperature difference between the CBD and parklands of $6^{\circ} \mathrm{C}$; with an average of $1.5^{\circ} \mathrm{C}$. The maximum temperature difference occurs around sunrise and the winter UHI effect is more marked than in summer.

Using a sky view factor which includes information of the wind (effective sky view factor, ESVF), the change in temperature depending on the height variation is in excess of $1^{\circ} \mathrm{C}$. This, in connection with a projected temperature increase due to climate change, has major implications to energy use and carbon emissions in the future.

A micro-scale urban model (ENVI-Met) has been employed to study the influence of building height on the surrounding UHI effect. The modeling of a simple street canyon displays the relation between building height and street width and hence confirms the results exhibited by the effective sky view factor. However, the simple street canyon simulations with ENVI-Met show that when building height reaches street width, the increase in temperature at street level stops and even reverses for higher building heights. The model may lack significant processes (e.g. heat transfer between inside and outside of the buildings). Observations show that shading of surface area and heat storage processes in the walls are important contributions to the atmospheric temperature.

ENVI-Met Version 3.1 does not include heat storage in building walls. Heat transport between inside and outside of buildings is treated as an in situ process. This missing process is a possible explanation in the reversal of the diurnal temperature change in the simple cases when building height reaches street width. It is also likely the reason that a lower average temperature is modeled in a complex city setting when double building height is simulated and compared to the control case.

Further investigation of the atmospheric processes and their effect on the near surface temperature is needed. Modeling here is still in progress and further simulations, especially for the complex Adelaide CBD, cases are necessary.

Keywords: $\quad$ Urban heat island, energy balance, micro-scale modeling, surface characteristics 


\section{INTRODUCTION}

City size measured by population and an increased Urban Heat Island (UHI) effect are well correlated (Oke, 1973; Torok et al., 2001). However, results from North American and European cities are likely to display a larger urban heat island effect than Australian cities (Torok et al., 2001). Australian cities in general grow outwards not upwards with an increase in population, but limited space in Australian settlements will lead to a change in the city growth in the next decades. Increase in building heights in city areas are already proposed in Adelaide to account for the projected population growth, (DPLG, 2012).

The urban heat island in Adelaide was studied as early as the 1970s and displayed an enhanced temperature in the central business district (Lyons, 1974). Since winter 2010 an enhanced network of temperature sensors is operational in Adelaide (Ewenz et al., 2012; Guan et al., 2013). Traverses, using a car equipped with meteorological instrumentation (Lyons, 1974; Ewenz et al., 2012) exhibits the small scale variation of the near surface temperature in the Adelaide city street canyons.

Changes to building heights in the Adelaide CBD, as proposed by the city planners will change the overall temperature distribution in the city. Simple models, like the sky view factor calculations utilising threedimensional building information, can exhibit what the future temperature layout will be (Zhu et al., 2013). A micro-scale numerical urban model focusing on the atmospheric dynamics as well as the surface-plantatmosphere interaction exhibits details of the atmospheric setting in street canyons, such as temperature gradients across streets due to variation in shade, ventilation effect of street layout and effect of green areas on the surrounding, with a horizontal resolution of up to $5 \mathrm{~m}$. The urban model used is ENVI-Met (Bruse, 1999; Bruse \& Team, 2012; Bruse and Fleer, 1998) and is freely available.

Modeling the urban micro-climate provides two major insights into processes associated with an urban heat island. Firstly, several aspects, such as changes in building height and street width, can be addressed which are difficult to obtain in a city setting. This approach is helpful for investigating the effect of climate change, in order to inform planning decisions. Secondly, a much finer spatial and temporal resolution of temperature variations can be examined compared to the established iButton network. As well as temperature, the distribution of other atmospheric variables such as wind speed and direction, radiation, sensible and latent heat fluxes (all of which impinge on the UHI), can be obtained. The urban micro-climate model allows detailed horizontal and vertical profiles of parameters to be extracted.

\section{METHODOLOGY AND DATA}

Since 2010, a network comprising twenty temperature sensors were installed at four metres above street level in Adelaide's central business district (CBD) and the surrounding parks (Figure 1). Each sensor consisted of a miniature encapsulated temperature sensor and logger, the Thermochron iButton series DS1921H-F5, DS1921Z-F5 and the DS1922L-F5 manufactured by Maxim Integrated Products (Dallas, Texas). The sensors were mounted in self-made radiation shields. All iButton temperature sensors were carefully calibrated. In addition data from ten stations from the Bureau of Meteorology (BoM) and the Environmental Protection Agency (EPA) were analysed.

The three-dimensional micro-climate model ENVI-met (Bruse \& Team, 2012) is designed to simulate the surface-plant-air interactions in urban environments. The typical resolution of the model ranges from $0.5 \mathrm{~m}$ to $10 \mathrm{~m}$ in space with a maximum time step of 10 seconds. The total simulation time is 1 to 2 days. This resolution allows the analysis of small-scale interactions between individual buildings, surfaces and plants. The model is based on the thermo-hydrodynamic set of equations. Calculations include long and short wave radiative fluxes accommodating shading and reflection from buildings and vegetation, sensible and latent heat fluxes from vegetation and photosynthetic energy exchange, surface and wall temperature on a grid point and wall basis, water and heat exchange into the soil as well as bio-meteorological parameters and inert gas and particle dispersion of leaves and surfaces (Bruse, 1999; Bruse \& Team, 2012; Bruse and Fleer, 1998). 


\section{MODEL SETUP}

Two investigations were setup for the ENVI-Met model. At first a simple synthetic street canyon case was initialized. This simple case was utilised to study the effect of building height on the street level temperature distribution. Here the street was defined as asphalt with an adjacent concrete footpath orientated northsouthward with a width of $48 \mathrm{~m}$. The buildings either side of the street varied from $0 \mathrm{~m}$ to $50 \mathrm{~m}$ height between the different simulations. The wind at $10 \mathrm{~m}$ above ground was $1.5 \mathrm{~m} / \mathrm{s}$ from the south-east.

The initial atmospheric temperature at $2 \mathrm{~m}$ above ground was set to $26^{\circ} \mathrm{C}$. The model was run for Adelaide on the 6th of January 2013. The average surface temperature for each hour was calculated. The meteorological input data were acquired from the iButton network and the radiosonde data from Adelaide airport; the latter is available from University of Wyoming upper air data sets (UWYO, 2011).

The second model experiment represents a $500 \mathrm{~m}$ by $500 \mathrm{~m}$ area in the Adelaide CBD with high rise buildings, referred to as the NAB case. The lower model boundary was evaluated from a three-dimensional building height, a surface material and a tree data set, provided by the Adelaide City Council (ACC). Temperature, wind speed and direction were kept the same as the above street canyon cases.

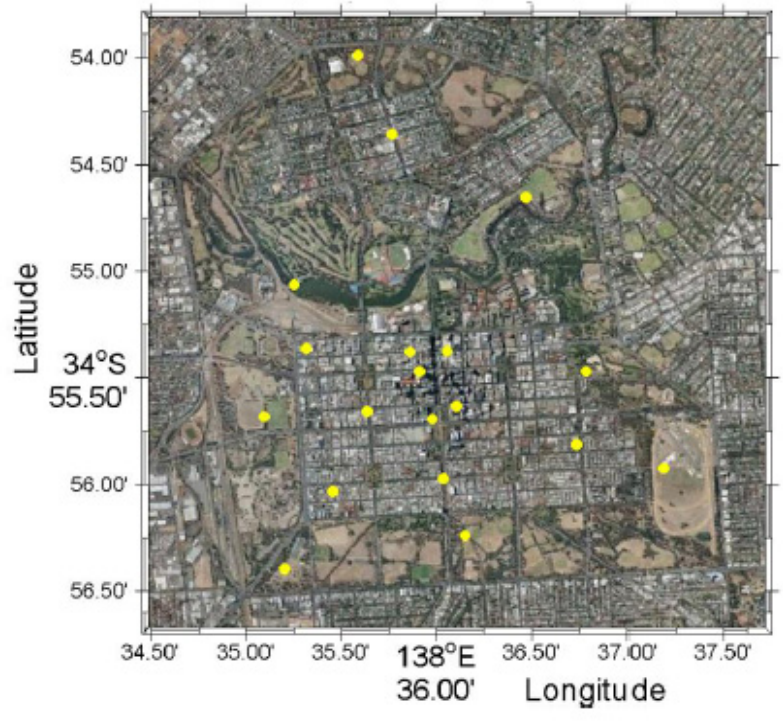

Figure 1: Image of the Adelaide CBD and surrounding parks. The temperature monitoring sites are displayed as yellow dots. Image courtesy of https://maps.google.com.au ENVI-Met was run for the $6^{\text {th }}$ of January 2013.

\section{RESULTS}

\subsection{Effect of building height variation on near surface temperature field}

The diurnal temperature variation displays a minimum temperature around sunrise and a maximum temperature around noon; Figure 2. The range of the diurnal variation increases with building height. The

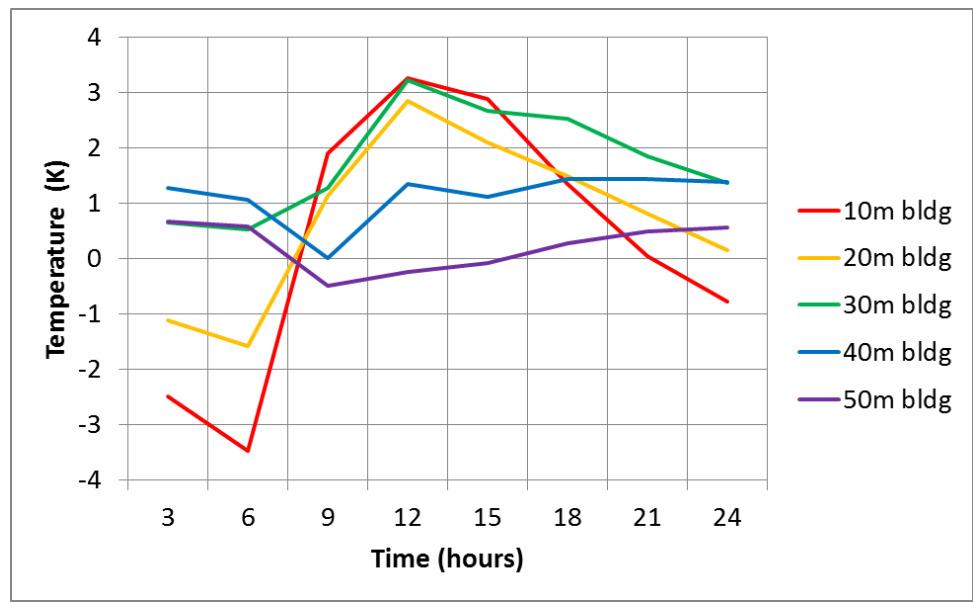

Figure 3: Diurnal variation of average temperature between the buildings at the surface in $\mathrm{K}$ for a building height of $0 \mathrm{~m}$ (black solid line) to a building height of $50 \mathrm{~m}$ (purple solid line). The colour coding for the various height cases is shown on the right. control case (building heights of $0 \mathrm{~m})$ displays a range of less than $10 \mathrm{~K}$, while the $40 \mathrm{~m}$ and $50 \mathrm{~m}$ building height cases exhibit a diurnal range of over $20 \mathrm{~K}$. The diurnal temperature distributions for the two highest cases $(40 \mathrm{~m}$ and $50 \mathrm{~m}$ building height) are very similar. Figure 3 displays the differences between cases varying by $10 \mathrm{~m}$ in building height. Here the difference between the $10 \mathrm{~m}$ case and the $0 \mathrm{~m}$ case shows the largest change, while between $40 \mathrm{~m}$ and $50 \mathrm{~m}$ building height there is not much variation as previously mentioned. The street width is $48 \mathrm{~m}$; , hence between $40 \mathrm{~m}$ and $50 \mathrm{~m}$ the building height reaches the street width. 


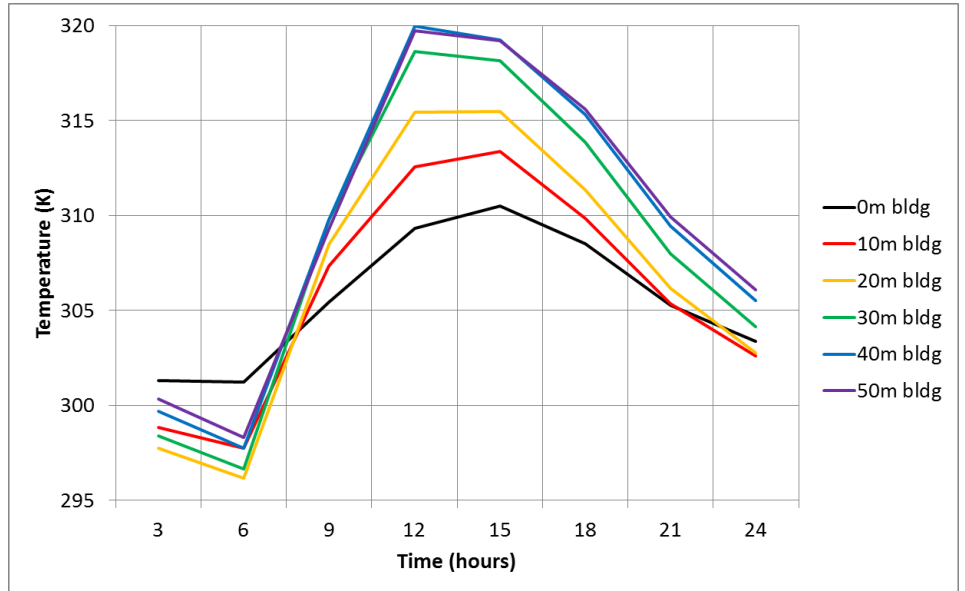

Figure 2: Diurnal variation of average temperature between the buildings at the surface in $\mathrm{K}$ for a building height of $0 \mathrm{~m}$ (black solid line) to a building height of $50 \mathrm{~m}$ (purple solid line). The colour coding for the various height cases is shown on the right.

\subsection{Effect of building height increase for CBD case}

Part of the city area was investigated in a real case scenario and compared to possible increases in building height. The NAB actual height case displays threedimensional information for the CBD buildings. At 6 am the temperature range at four metres above the surface is not large, $0.8 \mathrm{~K}$, over the model domain. The temperature is decreasing slightly towards the north of the domain, towards open North Terrace; Figure 4. Increasing the building heights to double height, seen in Figure 5, does not increase the temperature range and the average temperature over the domain is decreasing.

\section{DISCUSSION}

The simple street canyon simulations do exhibit what is expected for the urban heat island, the higher the building height, the higher the temperature in the street canyon. However the small change between the two cases at $40 \mathrm{~m}$ and $50 \mathrm{~m}$ suggests that two main processes are at work. Firstly, lower temperatures result from shading; especially in the narrow street channels where radiation from the sun may not reach the surface. Secondly, heat storage in buildings and walls, due to the larger heat capacity of the concrete walls and other building materials, leads to an increase in surrounding temperatures. ENVI-Met does not include heat storage in walls. Heat storage in walls and slow release of the heat over night is a major process causing the urban heat island effect. This missing process in ENVI-Met is therefore the most likely factor in the similar diurnal temperature change in the simple cases between the two heights of $40 \mathrm{~m}$ and $50 \mathrm{~m}$. In the $50 \mathrm{~m}$ height case the building height reaches the street width and shading of the surface area is more significant. It is also likely the cause for the lower average temperature for the NAB double height simulation.

An increase of the near surface temperatures in ENVI-Met results from heat storage in the soil or surface material. This process explains the change in temperature with changing building heights in the simple cases. Further investigation of the relevant processes and their effect on the near surface temperature is needed.

\section{CONCLUSION}

The modeling of a simple street canyon displays the relation between building height and street width. When building height reaches street width, shading processes and heat storage processes change their contribution to the temperature field near the surface. The nighttime heat release depends on the viewing field of the clear sky. The latter process is clearly simulated in the model. However, the missing storage in building walls in ENVI-Met reduces the heat island effect for higher buildings. Further investigations of this process are necessary to understand the model quality. An improved ENVI-Met version needs to include storage of heat in building walls in order to effectively simulate the urban heat island effect. 

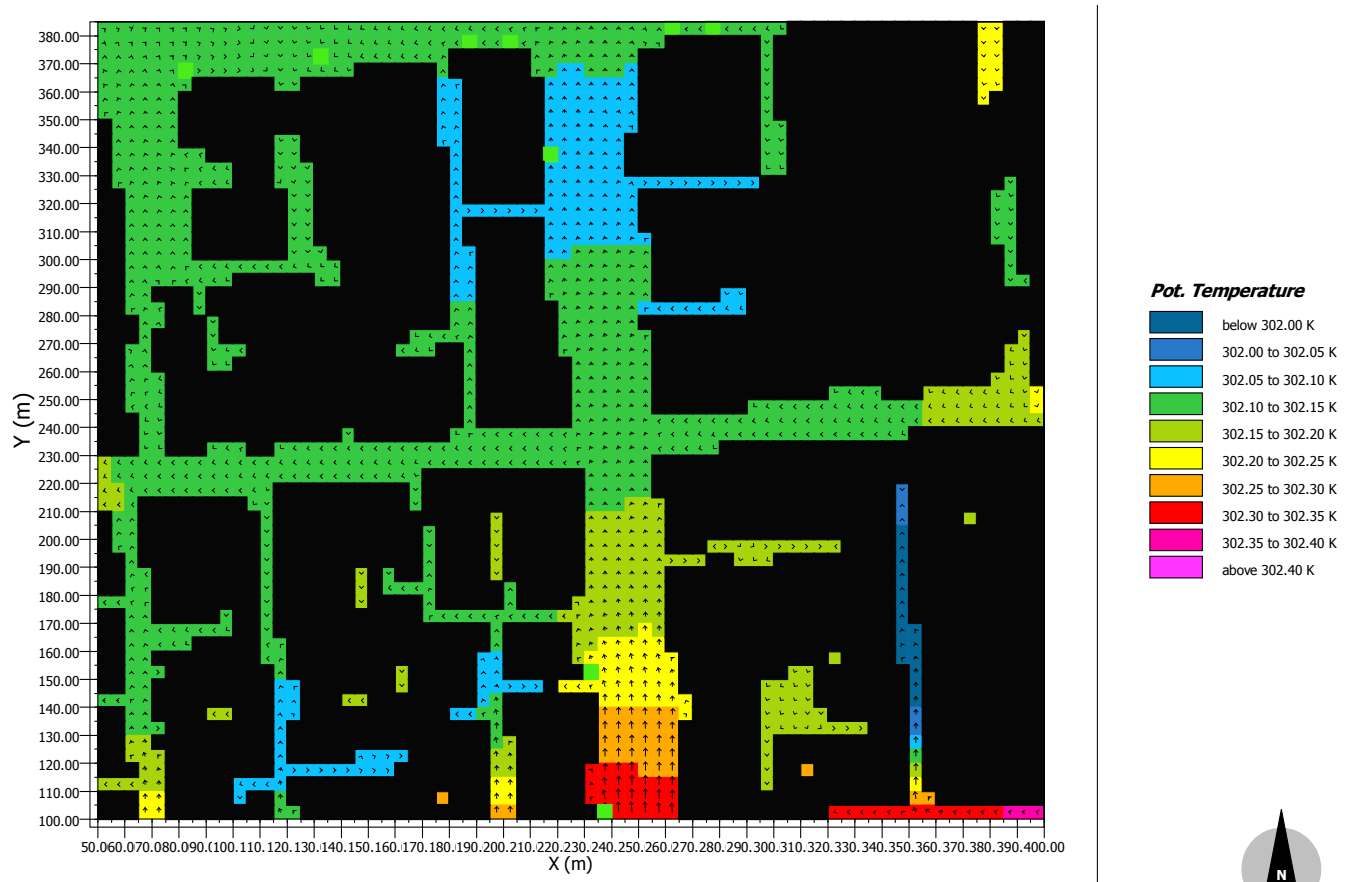

Figure 4: NAB, actual height: $6^{\text {th }}$ January 2013, 6AM. View of the temperature and wind fields at $4 \mathrm{~m}$ height (temperatures in Kelvin, subtract 273.15 to convert to Celsius). The colour coding is for a temperature range of $0.4^{\circ} \mathrm{C}(0.4 \mathrm{~K})$, blue (cooler) to pink (warmer). The near surface wind field is displayed by arrows, the length of each arrow represents the wind speed and the arrow's direction displays the wind direction.
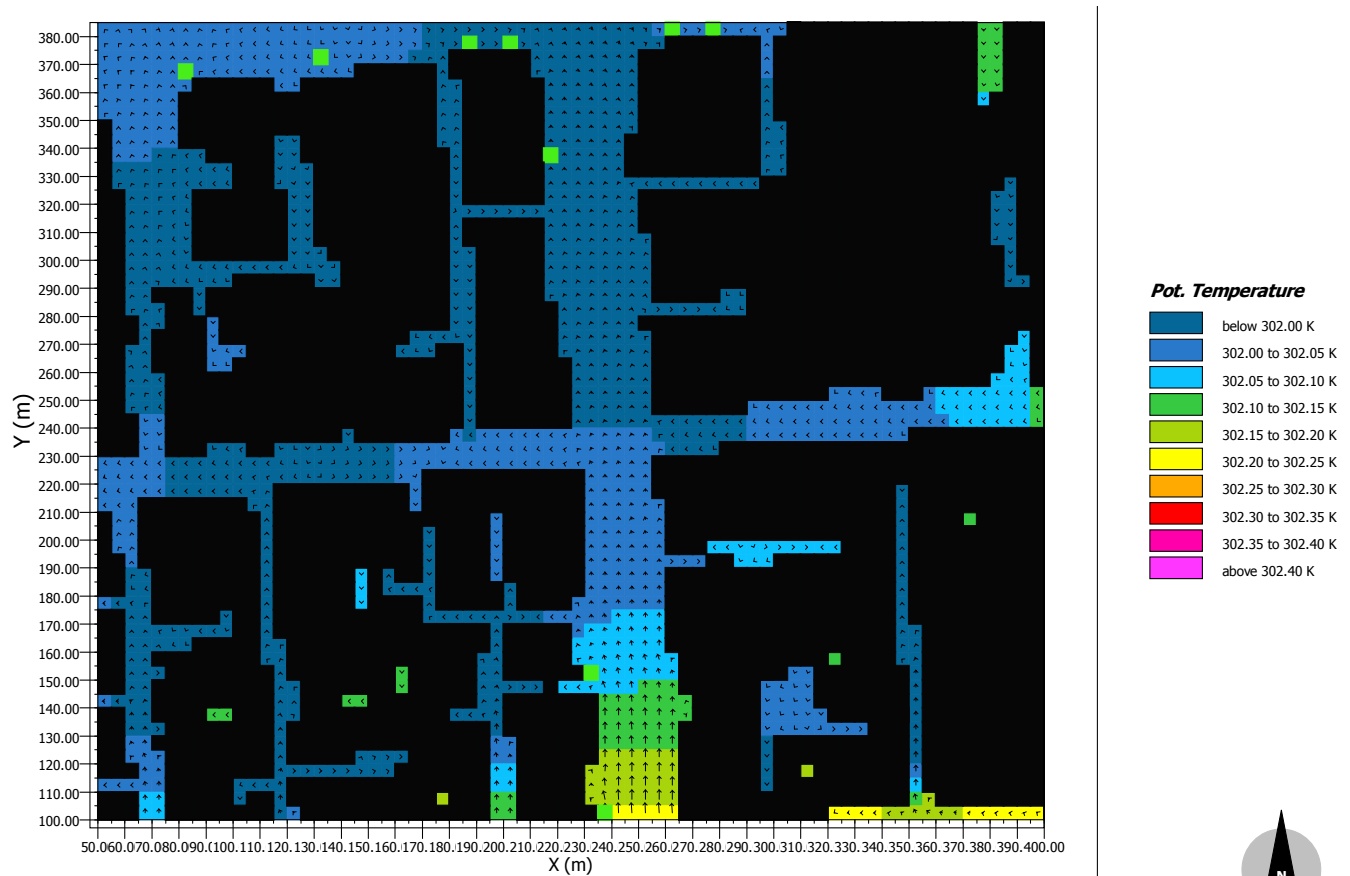

Figure 5: NAB, double height: $6^{\text {th }}$ January 2013, 6AM. View of the temperature and wind fields at $4 \mathrm{~m}$ height. For details see Figure 4. 


\section{ACKNOWLEDGMENT}

The authors like to acknowledge the UHI research group at Flinders University team and the help of many students in the field. Funding was provided by South Australian departments and some local governmental organisations, namely DENR, ACC, DPC, DPLG, ETSA. The EPA and the BoM provided data from their local station network and the University of Adelaide and Flinders University provided support and funding.

\section{REFERENCES}

Benger, S. (2012). Personal communication; $x, y$ data set in $1 \mathrm{x} 1 \mathrm{~m} 2$ resolution from the ACC: 3D, roads and path and trees data sets, personal communication. Flinders University, School of the Environment.

Bruse, M. (1999). Die Auswirkung kleinskaliger Umweltgestaltung auf das Mikroklima. Entwicklung des prognostischen numerischen Modells EnviMet zur Simulation der Wind, Temperatur und Feuchteverteilung in städtischen Strukturen. PhD thesis Ruhr University, Bochum, Germany, 217pp.

Bruse, M. and H., Fleer (1998). Simulating surface-plant-air interactions inside urban environments with three dimensional numerical model. Environmental Modelling \& Software, 13, 373-374.

Bruse, M. and Team (2012). ENVI-met 3. http://www.envi-met.com/ [accessed 2 July 2012]

DPLG (Department of Planning and Local Government) (2012). The 30 year plan for Greater Adelaide. Available at http://www.dplg.sa.gov.au/plan4adelaide/html/plan.cfm [accessed 25 August 2013]

Ewenz, C.M., J.M. Bennett, C. Kent, Vinodkumar, H. Guan and R. Clay (2012). The Adelaide Urban Heat Island: Spatial and temporal aspects . Proceedings ICUC8 - 8th International Conference on Urban Climates, 6th-10th August, 2012, UCD, Dublin Ireland. Available at https://www.dropbox.com/sh/4x3vtvxg031mja4/vBgKETszNT [accessed 25 August 2013]

Guan, H., J.M., Bennett, C.M., Ewenz, S., Benger, Vinodkumar, S.H., Zhu, R.., Clay, and V., Soebarto (2013). Characterisation, interpretation and implications of the Adelaide Urban Heat Island. Flinders University, Adelaide, South Australia. Available at http://hdl.handle.net/2328/26839 [Accessed 25 August 2013]

Kent, C. (2010). The Adelaide Urban Heat Island. Honours thesis Flinders University. 74pp.

Lyons, T.J. (1974) Adelaide's urban climate. Research paper no. 12, The Flinders Institute for Atmospheric and Marine Sciences, 31 pp.

Maxim Integrated Products, Inc. 160 Rio Robles San Jose, CA 95134 USA http://www.maximic.com/products/ibutton/ [accessed 30 June 2012]

Oke, TR. (1973). City size and the urban heat island. Atmospheric Environment, 7, 769-779.

Torok, S. J., C.J., Morris, C., Skinner, and N., Plummer, (2001). Urban heat island features of southeast Australian towns. Australian Meteorological Magazine, 50(1), 1-13.

UWYO (University of Wyoming) (2011) Upper air data available at http://weather.uwyo.edu/upperair/sounding.html [accessed 25 August 2013]

Zhu, S., H., Guan, J.M., Bennett, R., Clay, C.M., Ewenz, S., Benger, A., Maghrabi, and A. C., Millington (2013). Influence of sky temperature distribution on sky view factor and its applications in urban heat island. International Journal of Climatology,33(7), 1837-1843. 